\title{
Survival Analysis of Time to Abscission of Blueberry Leaves Affected by Septoria Leaf Spot
}

\author{
P. S. Ojiambo and H. Scherm
}

Department of Plant Pathology, University of Georgia, Athens 30602.

Accepted for publication 29 September 2004.

\begin{abstract}
Ojiambo, P. S., and Scherm, H. 2005. Survival analysis of time to abscission of blueberry leaves affected by Septoria leaf spot. Phytopathology 95:108-113.

In the southeastern United States, Septoria leaf spot, caused by Septoria albopunctata, can result in premature defoliation of blueberry plants during summer and fall, thereby reducing yield potential for the following year. The effects of disease severity and leaf attributes (leaf age and leaf location in the canopy) on the dynamics (timing and extent) of defoliation were quantified in field plots of Premier rabbiteye blueberry (Vaccinium ashei) in 2002 and 2003. In each year, 50 shoots were selected for assessment in early spring, and all leaves on these shoots $(n=$ 410 and 542 in 2002 and 2003, respectively) were monitored individually for disease progress and time of abscission at 3- to 10-day intervals throughout the season. In both years, disease progress was characterized by an exponential increase in disease severity up to late September, followed by a decline toward the end of the assessment period in late November. Defoliation was sporadic up to late August, followed by more

rapid and sustained levels of leaf loss. Abscission of severely infected leaves could explain the decline in disease severity toward the end of the season. Final disease severity (i.e., disease severity on the last assessment date before leaf drop) was highest for leaves that abscised early and lowest for leaves that had not abscised by the end of the assessment period. Survival analysis revealed that older leaves (located on the lower halves of shoots) and leaves with high levels of disease ( $\geq 5$ spots/leaf at the time of fruit harvest in mid-June) abscised significantly $(P<0.0001)$ earlier than younger leaves and leaves with lower disease severity. Relative to their respective reference groups, mean times to abscission were $\approx 2$ weeks shorter for the older leaf group and $\approx 3$ weeks shorter in the leaf group afflicted by high disease severity. When an accelerated failure time model was fitted to the data, the resulting parameter estimates indicated that each additional leaf spot present at harvest accelerated time to leaf abscission (expressed using late August as a starting point) by 1.9 and $4.5 \%$ in 2002 and 2003, respectively. Leaf location in upper or lower portions of the canopy had no significant effect on time to abscission $(P>0.05)$.
\end{abstract}

Blueberry is the second most important fruit crop in Georgia and currently is grown on 3,220 ha statewide (3). Approximately $90 \%$ of the area is planted to rabbiteye blueberry (Vaccinium ashei), with the remainder devoted to production of southern highbush blueberry ( $V$. corymbosum interspecific hybrids) (29). Both species can be affected by foliar diseases, with disease susceptibility being strongly cultivar dependent (28). Among these foliar diseases, Septoria leaf spot, caused by Septoria albopunctata, is of particular concern to blueberry producers in Georgia and other southeastern states $(7,28)$. Symptoms are characterized by small circular leaf lesions with white to tan centers and purple margins. The optimum temperature for pathogen growth and disease development is 24 to $28^{\circ} \mathrm{C}$ (22). In Georgia, foliar symptoms of Septoria leaf spot appear first by early May and then increase rapidly between June and September (P. S. Ojiambo, unpublished data).

When left uncontrolled, Septoria leaf spot can result in premature defoliation (henceforth referred to simply as defoliation) in late summer or early fall $(4,5,7)$. In blueberry, it is advantageous to retain leaves for as long as possible during the fall to enhance the ability of the plants to set flower buds (9). Indeed, in field experiments involving mechanical leaf removal treatments, Lyrene (20) demonstrated that early fall defoliation of rabbiteye blueberry resulted in a significantly lower percentage of nodes that produced flower buds the following spring. Similar results were obtained with southern highbush blueberry (38). The reduc-

Corresponding author: H. Scherm; E-mail address: scherm@uga.edu

DOI: 10.1094/PHYTO-95-0108

(C) 2005 The American Phytopathological Society tion in flower bud set associated with defoliation may be due to the elimination of photoreceptors on removed leaves or a lowering of carbohydrate reserves during critical periods in the fall (20).

The effect of Septoria leaf spot-induced (as opposed to mechanical) fall defoliation on reproductive development of blueberry has not been studied previously. Thus, there is a need for quantitative information on the dynamics of defoliation and how it relates to disease progress. Studies with mechanical leaf removal showed that both the extent and timing of defoliation affected yield $(20,38)$ and that defoliation is affected by leaf attributes such as age (older leaves abscise earlier) and leaf location in the canopy (leaf drop on shoots in the lower canopy of the bush occurs earlier) $(24,28)$. Based on these considerations, the goal of this study was to model the timing and extent of abscission of blueberry leaves in relation to Septoria leaf spot severity, leaf age, and leaf location in the canopy in order to provide estimates of the probability of leaf loss at given times during the growing season.

\section{MATERIALS AND METHODS}

Field site and data collection. The study was carried out in an experimental blueberry planting at the University of Georgia Horticulture Farm near Athens in 2002 and 2003. The planting was established in 1988 and consisted of alternating rows of $V$. ashei cvs. Premier and Climax. Maintenance of the planting, including fertilization, pruning, and weed control, followed commercially recommended practices (2). Supplemental overhead irrigation was applied as needed, primarily during the fruit maturation phase in the dry 2002 growing season. No fungicides were 
applied during the 2-year study period. Records of daily air temperature and amounts of precipitation were obtained from an onsite electronic weather station that is part of the Georgia Automated Environmental Monitoring Network (14).

On Premier, which is highly susceptible to Septoria leaf spot (28) but not to other foliar diseases, 50 shoots were selected arbitrarily from 12 bushes during the period of leaf expansion (23) on 22 April and 24 March in 2002 and 2003, respectively. Each shoot was tagged at its base, and its position above the ground was measured to the nearest centimeter to provide a measure of leaf location in the canopy. Each leaf present on the distal $20 \mathrm{~cm}$ of these shoots was assigned a unique number for tracking during the respective year of the study. New leaves that emerged on the selected shoots as a result of shoot growth as the season progressed were tracked similarly. No new leaves emerged on selected shoots after 31 May 2002 and 13 June 2003, resulting in a population of 410 and 542 leaves that were monitored in 2002 and 2003, respectively. A distinction was made between older leaves (on the lower halves of the shoot segments) and younger leaves (those on the upper halves of the shoots), to which values of 0 and 1 were assigned, respectively.

Leaves were assessed individually for severity of Septoria leaf spot beginning immediately after shoots were tagged in early spring, whereby disease severity was expressed as number of spots per leaf. For the first 6 to 8 weeks, disease severity was assessed at 3- to 5-day intervals, after which assessments continued every 7 to 10 days for the remainder of the season. The last disease assessment was made on 15 November 2002 and 8 November 2003, after which necrosis associated with natural leaf senescence made leaf spot counts impossible. Leaves were monitored for abscission (described below) for another 3 weeks after the last disease assessment date.

The numbering system for tracking individual leaves enabled us to determine the time of abscission of each leaf based on the absence of that leaf from the node on which it was present on the previous assessment date. However, because assessment dates were 3 to 10 days apart, it could not be determined exactly on which day leaf abscission occurred; instead, it was assumed that the time of abscission for a leaf that dropped between two successive assessment dates was at the midpoint of the two assessment dates. Based on this estimate of time of abscission, time to abscission, $T$, was calculated for each leaf using 23 August 2002 (day of the year 235) or 28 August 2003 (day 240) as starting dates. These dates were chosen because they corresponded to the assessment dates that marked the transition from negligible, sporadic leaf loss to the onset of more sustained levels of defoliation (Fig. 1). Any defoliation that occurred prior to these dates, mainly due to factors other than disease, was not considered in the analysis.

Descriptive analysis. For each year separately, monitored leaves were assigned to four classes based on their $T$ values. In 2002 , three of the groups corresponded to $T$ values of $<50,50$ to 80 , and $>80$ days after 23 August, while the fourth group comprised leaves that had not abscised by the end of the assessment period. In 2003, groups were defined similarly, except that the first three groups had $T$ values of $<40,40$ to 70 , and $>70$ days after 28 August. Different classes were used in the 2 years due to differences in the dynamics of defoliation (Fig. 1). For each class, the distribution of final disease severity values among all the leaves within that class was examined using box-whisker plots generated with the UNIVARIATE procedure in SAS (version 8.2; SAS Institute, Cary, NC), whereby final disease severity was defined as the number of spots per leaf on the disease assessment date prior to leaf drop. Separately for the 2 years, differences among the four classes in the distribution of final disease severity values were tested for significance using the Kruskal-Wallis test (32), a nonparametric test of the null hypothesis that the distribution of a response is the same in multiple groups.
Survival analysis concepts. Data that describe time to an event (e.g., time to leaf abscission) generically are referred to as survival data or failure time data. Conventional statistical techniques such as linear regression analysis are inappropriate for these data because complete knowledge of survival times may not be available due to censoring, most commonly because the period of observation ends before all individuals experience the event of interest. Furthermore, survival times often do not follow a normal distribution (17). In this study, the data set contained multiple censored observations (i.e., leaves that had not abscised by the end of the assessment period) and time to leaf abscission, the dependent variable, is readily interpreted as a "survival time" $(10,30,39)$; therefore, survival analysis techniques were used to describe and model the data. Central to this analysis is the determination of the leaf survival distribution function $S(t)=P(T \geq$ $t$ ) which gives the probability of observing a survival time $T$ larger than or equal to some value $t$.

A fundamental assumption of survival analysis is that observations for different individuals are statistically independent. This was a potential concern in the present study, where times to abscission of leaves located on the same shoot could have been correlated. To test for the validity of the independence assumption, we used the ARIMA procedure in SAS to determine whether times to abscission of leaves within shoots were autocorrelated. Only 2 and 5 of the 50 shoots included in 2002 and 2003, respectively, showed significant $(P<0.05)$ autocorrelation patterns (data not shown), suggesting that observations from different leaves on the same shoot were independent.

Comparison of survival distribution functions among groups of leaves. Binary variables were constructed for disease severity at harvest $(<5$ or $\geq 5$ spots per leaf on 14 and 20 June in 2002 and
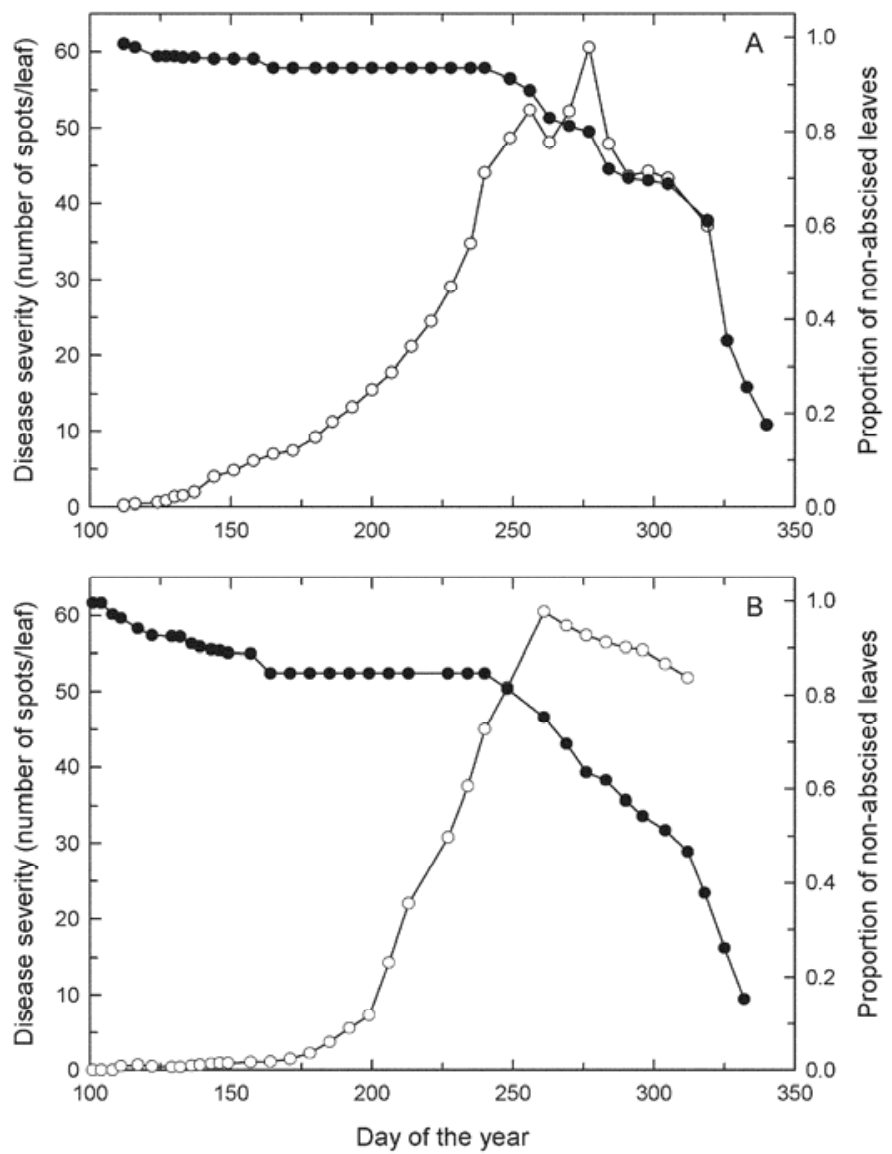

Fig. 1. Temporal progress of Septoria leaf spot severity (O) and abscission ( of individual leaves of Premier rabbiteye blueberry in a field study in Georgia in $\mathbf{A}, 2002(n=410)$ and $\mathbf{B}, 2003(n=542)$. 
2003 [days 165 and 171], respectively, marking the time when $\approx 50 \%$ of the fruit had been harvested), leaf age (older or younger leaves on the shoot), and leaf location in the canopy $(\leq 80$ or $>80 \mathrm{~cm}$, corresponding to aboveground shoot position in lower and upper portions of the canopy, respectively). For each leaf group defined by these binary variables, leaf survival distribution functions were obtained using the Kaplan-Meier estimation within the LIFETEST procedure in SAS (1). Differences between leaf groups were compared using the log-rank test (11).

Modeling leaf survival. The accelerated failure time (AFT) model $(1,30)$ was used to parameterize the effects of initial disease severity (DS, expressed as number of spots per leaf), leaf age (LA, a binary variable as defined above), and leaf location in the canopy (LL, in centimeters aboveground) on leaf survival. This modeling approach was selected after initial analyses indicated that the assumptions of the proportional hazards model (1), an alternative model for survival times, were not satisfied for the 2003 data set. Technical details of these two modeling approaches have been reviewed by Scherm and Ojiambo (30) and are discussed extensively by Allison (1).

The AFT model was of the form $\log _{\mathrm{e}} T=\beta_{0}+\beta_{1} \mathrm{DS}+\beta_{2} \mathrm{LA}+$ $\beta_{3} L L+\sigma \varepsilon$, where $\varepsilon$ is a random error term and $\beta_{0}, \beta_{1}, \beta_{2}, \beta_{3}$, and $\sigma$ are parameters to be estimated. The model was implemented with the SAS procedure LIFEREG using the Weibull model to describe the underlying survival time distribution. This choice of probability distribution was based on comparing the log-likelihoods for the fitted survival time distribution models (Table 1). The Weibull model consistently had lower log-likelihoods in the 2 years, and lower absolute values of log-likelihoods correspond to a better model fit $(1,11)$. Final AFT model parameter estimates were obtained by dropping nonsignificant terms $(P>0.05)$ and refitting the model.

\section{RESULTS}

Disease progress and abscission of individual leaves. In 2002, symptoms of Septoria leaf spot first were observed at the end of April, followed by an exponential increase in disease severity up to late September (Fig. 1A). Thereafter, disease severity decreased until the end of the assessment period, presumably because of abscission of severely infected leaves. In 2003 , onset of disease occurred nearly 2 months later than in the previous year (Fig. 1B), yet the time when the disease progress curve peaked and the average disease severity at that time ( $\approx 60$ spots per leaf) were similar for the 2 years. Thus, after an initial delay, the disease progressed more rapidly in 2003 than in 2002 .

The earlier disease onset in 2002 may have been associated with warmer spring temperatures. For example, the monthly mean temperature for April was $18.1^{\circ} \mathrm{C}$ in 2002 but only $15.5^{\circ} \mathrm{C}$ in 2003. By contrast, the more rapid disease progression during the second year likely was due to increased precipitation. The total amount of rain recorded between July and September was $482 \mathrm{~mm}$ in 2003 compared with $236 \mathrm{~mm}$ in 2002.

In 2002, very little defoliation was observed before the end of August (Fig. 1A). By the end of the first week of September, defoliation exceeded $10 \%$, and by mid-November, approximately one-third of all leaves had abscised. This was followed by a steep

TABLE 1. Comparison of four models to describe the survival distribution for estimating differences in time to abscission of individual leaves of Premier rabbiteye blueberry in a field study in Georgia in 2002 and 2003

\begin{tabular}{lcccc}
\hline & \multicolumn{4}{c}{ Log-likelihood } \\
\cline { 2 - 5 } Year & Exponential & Log-logistic & Log-normal & Weibull \\
\hline 2002 & -423.5 & -311.0 & -325.9 & -282.3 \\
2003 & -546.7 & -503.1 & -525.9 & -455.6 \\
\hline
\end{tabular}

increase in defoliation until early December, at which time $>80 \%$ of the leaves had dropped. In 2003, $\approx 15 \%$ of the leaves abscised before the end of May, followed by no additional defoliation until late August (Fig. 1B). This early leaf loss in the spring was unusual and followed a blossom blight epidemic (caused by Botrytis cinerea), whereby dehiscent, infected corollas, upon landing on leaf surfaces, incited large necrotic areas, ultimately leading to abscission of affected leaves. Following a period of absence of defoliation during the summer, leaf abscission increased steadily starting in early September and reached $>80 \%$ by the end of the assessment period in late November.

Distribution of time to leaf abscission. In both years, final disease severity was highest for leaves that abscised early (i.e., had the shortest $T$ values) and lowest for leaves that had not abscised by the end of the assessment period (Fig. 2). Leaves with intermediate $T$ values also had intermediate levels of disease. Using the Kruskal-Wallis test, the distributions of final disease severity values among the four defoliation time classes were different as indicated by highly significant $(P<0.0001$, df $=3) \chi^{2}$ values of 217.9 and 210.7 in 2002 and 2003, respectively.

Comparison of survival distribution functions among groups of leaves. In both years, disease severity at harvest and leaf age had highly significant $(P<0.0001)$ effects on survival of individual leaves, whereas leaf location in the canopy was marginally significant $(P=0.0347)$ in 2002 but not significant $(P=$
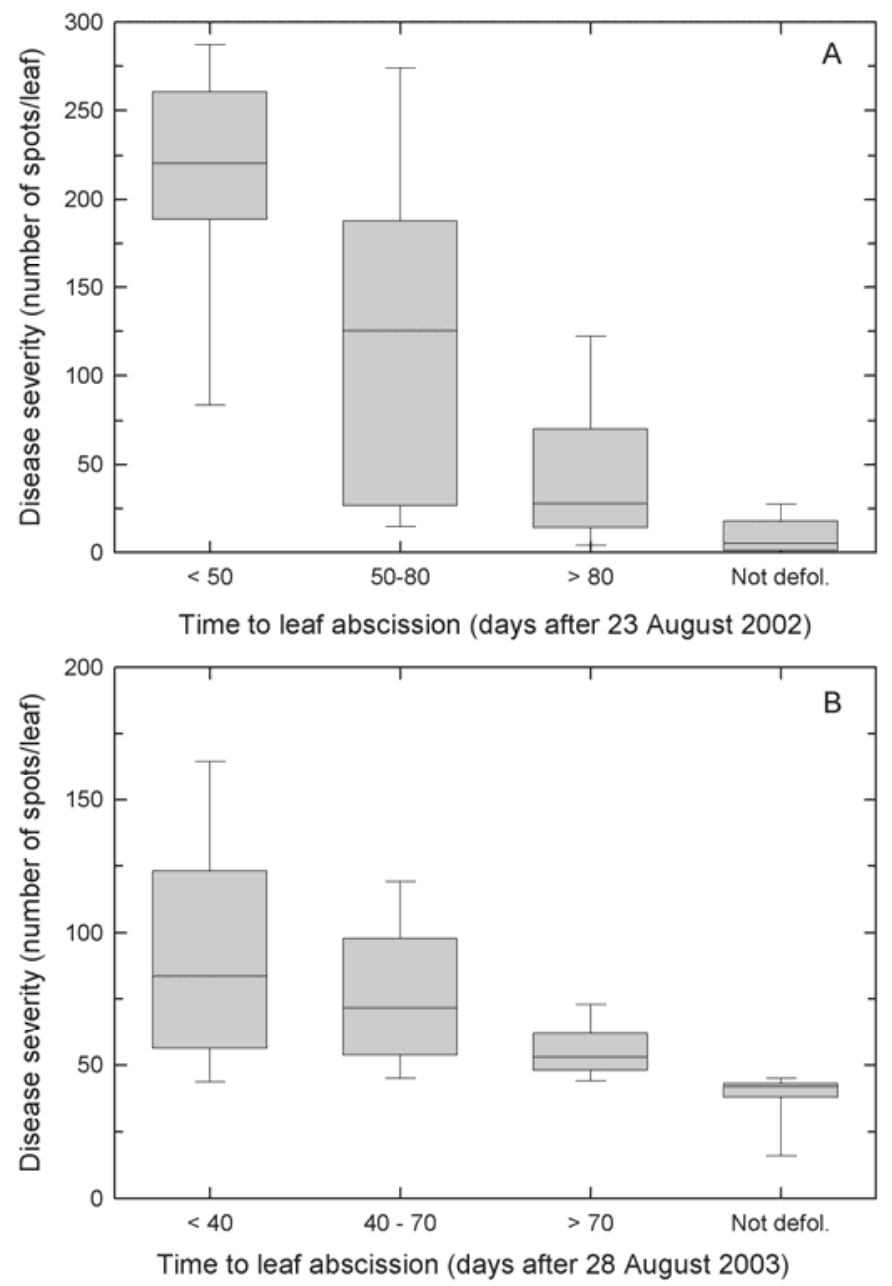

Fig. 2. Box-whisker plots showing the distribution of Septoria leaf spot severity values for individual leaves of Premier rabbiteye blueberry that abscised at different times in a field study in Georgia in A, $2002(n=383)$ and B, $2003(n=459)$. The boxes represent the interquartile range, the whiskers indicate the 5- and 95-percentiles, and the lines within the boxes represent median disease severity. Not defol. = leaves that had not abscised by the end of the assessment period in late November. 
0.2105 ) in 2003 (Table 2). For the two disease severity groups, the difference in leaf survival was evident from the estimated survival functions (Fig. 3). Each point on the survival function represents the probability that a leaf will survive (i.e., not abscise) until a given point in time. For example, in 2003, the estimated probability for a leaf to survive for 50 days after 28 August was 0.70 and 0.42 for leaves in the low ( $<5$ spots/leaf) and high ( $\geq 5$ spots/ leaf) disease severity groups, respectively (Fig. 3B). At the end of the assessment period, survival was zero for leaves with $\geq 5$ spots at harvest compared with a survival probability of 0.20 for leaves having $<5$ spots. In both years, mean survival times of leaves with low disease at harvest were $\approx 3$ weeks longer than those of leaves with a higher level of disease (Table 2).

Modeling leaf survival. The AFT model described the data well, with log-likelihood ratios of -282.3 and -455.6 in 2002 and 2003, respectively (Table 1). The parameter estimates and associated test statistics (Table 3) revealed that the effects of both disease severity at harvest (expressed as the number of spots per leaf) and leaf age on risk of leaf abscission was highly significant $(P<0.01)$ in the 2 years. Parameter estimates for leaf location in the canopy were not included in the final AFT model due to the nonsignificant $(P>0.05)$ effect of this variable in both years.

The dependent variable in the AFT model is $\log _{\mathrm{e}} T$; therefore, the parameter estimate for disease severity, $\beta_{1}$, can be used to calculate the relative change in survival time for each additional leaf spot using the formula $100 \% \times\left(e^{\beta 1}-1\right)(1)$. Based on this transformation, each additional spot present at harvest accelerated the time to abscission by 1.9 and $4.5 \%$ in 2002 and 2003, respectively. Similarly, relative differences in time to abscission between the two leaf age groups can be computed based on the estimate for $\beta_{2}$; this calculation indicated that older leaves were lost 13.1 and $40.7 \%$ earlier than younger leaves in 2002 and 2003, respectively.

\section{DISCUSSION}

This study provides the first quantitative description of the dynamics of premature defoliation of blueberry induced by Septoria leaf spot. Leaves with high disease severity or older leaves abscised earlier than those having low disease severity or younger leaves. The relative decrease in leaf survival due to Septoria leaf spot differed somewhat across the 2 years in that each additional leaf spot present at harvest accelerated time to abscission by $1.9 \%$ in 2002 and by $4.5 \%$ in 2003 . Assuming an average value of $\approx 3 \%$, the predicted time to abscission for a leaf with $n$ spots at harvest is only $(97 / 100)^{n} \times 100 \%$ as long as that of a disease-free leaf. Disease severity can reach very high levels on susceptible cultivars (28); therefore, the analysis revealed a considerable and highly significant quantitative effect of Septoria leaf spot on the risk of leaf abscission.
The ability of foliar diseases to incite premature defoliation in fruit crops has been documented for a number of pathosystems. In apple, for example, high levels of infection by Botryosphaeria obtusa, Phomopsis spp., or Marssonina coronaria have been shown to result in early leaf loss $(27,31)$. Severe defoliation of orange trees due to high levels of citrus greasy spot caused by
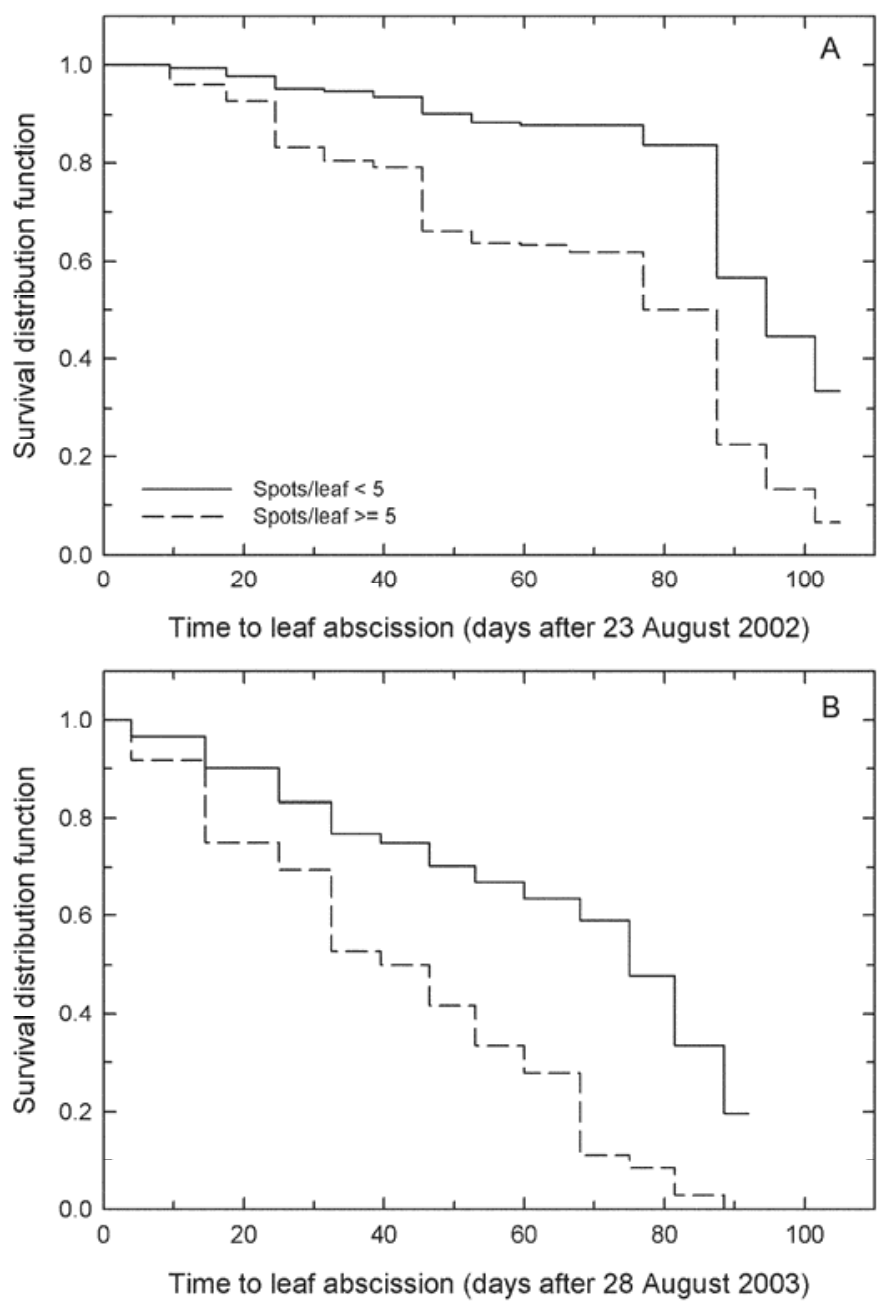

Fig. 3. Kaplan-Meier estimates of survival functions describing time to abscission of individual leaves of Premier rabbiteye blueberry in a field study in Georgia in A, $2002(n=383)$ and $\mathbf{B}, 2003(n=459)$. Leaves were classified according to severity of Septoria leaf spot in mid-June when $\approx 50 \%$ of the fruit had been harvested. The starting date for time to abscission was in late August, which marked the transition from a period of negligible, sporadic leaf loss to the onset of more sustained levels of leaf loss.

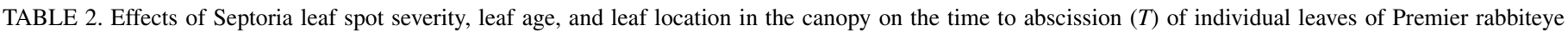
blueberry in a field study in Georgia in 2002 and 2003

\begin{tabular}{|c|c|c|c|c|c|c|}
\hline \multirow[b]{2}{*}{ Variable } & \multicolumn{3}{|c|}{2002} & \multicolumn{3}{|c|}{2003} \\
\hline & $n$ & $T$ (days) mean $\pm \mathrm{SE}$ & $P>\chi^{2}$ & $n$ & $T$ (days) mean $\pm \mathrm{SE}$ & $P>\chi^{2}$ \\
\hline \multicolumn{7}{|c|}{ Disease severity at harvest ${ }^{\mathrm{a}}$} \\
\hline$<5$ spots/leaf & 173 & $87.9 \pm 1.61$ & $\ldots$ & 423 & $64.3 \pm 1.32$ & $\ldots$ \\
\hline$\geq 5$ spots/leaf & 210 & $68.4 \pm 2.01$ & $<0.0001$ & 36 & $42.6 \pm 4.12$ & $<0.0001$ \\
\hline \multicolumn{7}{|l|}{ Leaf age ${ }^{b}$} \\
\hline Younger leaves & 174 & $84.5 \pm 1.64$ & $\ldots$ & 263 & $69.8 \pm 1.57$ & $\ldots$ \\
\hline Older leaves & 209 & $68.6 \pm 2.23$ & $<0.0001$ & 196 & $52.9 \pm 1.97$ & $<0.0001$ \\
\hline \multicolumn{7}{|l|}{ Leaf location ${ }^{\mathrm{c}}$} \\
\hline$\leq 80 \mathrm{~cm}$ & 122 & $68.7 \pm 2.88$ & $\ldots$ & 130 & $62.6 \pm 2.17$ & $\ldots$ \\
\hline$>80 \mathrm{~cm}$ & 261 & $81.3 \pm 1.51$ & 0.0347 & 329 & $62.6 \pm 2.38$ & 0.2105 \\
\hline
\end{tabular}

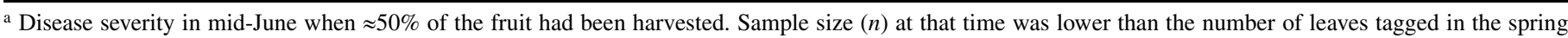
because some leaf loss had occurred due to factors other than Septoria leaf spot.

${ }^{\mathrm{b}}$ Leaves on the lower (older leaves) or upper (younger leaves) halves of the assessed shoots.

c Height above the ground of the assessed shoots. 
Mycosphaerella citri also has been reported (12). Similar effects of disease can occur in cherry, where infection by the leaf spot pathogen Cercospora circumscissa results in early and severe leaf loss (33). All these reports discussed the yield implications of disease-induced premature defoliation. In deciduous fruit, a large proportion of leaf carbohydrates $(6,25)$ and nitrogenous compounds (34) moves into the woody parts of the trees during autumnal senescence. These reserves play an important role in early growth of shoots and fruit the following spring (18).

In blueberry, retention of leaves throughout the fall enhances the ability of the plants to form flower buds (9). Based on mechanical defoliation experiments, Lyrene (20) determined that early fall defoliation of $V$. ashei reduced flower bud set; for example, only $1.4 \%$ of the apical nodes on defoliated shoots produced flower buds compared with $60 \%$ of the nodes on nondefoliated shoots. In experiments where leaves were removed from alternating nodes on each shoot, flower buds failed to form at the defoliated nodes, indicating that defoliation removes a nearby source of carbohydrates and thus reduces the potential of an auxiliary bud to be transformed into a flower bud (20). It also was suggested that premature defoliation in blueberry may reduce flower bud initiation by removing receptors of the short-day stimulus. In similar mechanical defoliation experiments on southern highbush blueberry, partial or complete premature defoliation inhibited flower bud set and resulted in lower fruit yields (38). The effects of disease-induced defoliation on flower bud induction and subsequent yield may be even more pronounced than those documented for mechanical defoliation, given the negative physiological effects of disease on infected leaves prior to leaf abscission. Indeed, in other pathosystems, leaf spots have been shown to lower yields by reducing the leaf area available for photosynthesis as well as the photosynthetic capacity of the remaining leaf area $(15,19)$. In a study to determine the effect of Septoria leaf spot on photosynthesis of blueberry leaves, Roloff et al. (26), using both rabbiteye and southern highbush blueberries, documented a reduction in photosynthesis in infected leaves, whereby net assimilation rate was lowered by approximately one-half at $20 \%$ disease severity and values approached zero for leaves with $>50 \%$ necrotic leaf area. Interestingly, the leaf area in which photosynthesis was impaired was approximately three times as large as the area covered by necrosis (26). Collectively, these studies illustrate the importance of maintaining disease-free foliage to maximize yields in the following growing season.

Our analysis also showed that older leaves are more likely to abscise prematurely compared with younger leaves. In addition to undergoing earlier natural senescence due to their advanced physiological age, older leaves also are likely to accumulate higher levels of disease, given their presence on the plant for a longer period of time. These increased disease levels, as discussed above, further increase the risk of premature leaf abscission. Differences in cumulative disease between older and younger leaves also have been reported for Septoria leaf spot on Eucalyptus nitens, caused by Septoria pulcherrima (13). Although differences in leaf susceptibility, inoculum availability, and environmental conditions during the season also may influence disease severity on leaves of different ages, no studies have been conducted to examine this relationship in detail.

Survival analysis proved to be a powerful tool for assessing the effect of disease severity and leaf age on time to defoliation. This method of analysis is dynamic in that it does not merely provide a "snapshot" at one particular point in time, but rather shows how the risk of defoliation changes over time with respect to a set of covariates. For example, unlike logistic regression, which requires that each observation be categorized as, say, low or high disease at a specified time, the dependent variable in survival analysis, $T$, is continuous, allowing for a more complete use of the information in the data. Similar conclusions were reached by Dungan et al. (10), who used growth equations and survival analysis to estimate the effect of date of emergence on the leaf lifespan of a winter-deciduous compared with an annual plant species. In that study, although growth equations precisely described leaf emergence of the two species, they obscured key differences between their leaf lifespans that were identified with survival analysis. In a study to describe the distribution of the time-dependent developmental trait "time to flowering" and compare differences in various maize genotypes, Vermerris and McIntyre (35) also reported that their conclusions were enhanced by using survival analysis compared with conventional statistical procedures. In plant pathology, previous applications of survival analysis, reviewed by Scherm and Ojiambo (30), have been limited $(8,16,21,37)$.

Although this study documented a strong and significant effect of Septoria leaf spot on premature defoliation and previous work established a link between premature defoliation and reduced return yields $(20,38)$, further research is needed to determine the physiological and quantitative effects of the disease on the processes involved in yield formation in blueberry. In addition, a more detailed examination of the temporal progress of the disease prior to defoliation is needed to identify host, pathogen, and environmental factors that determine epidemic development. Such information on disease progress, when integrated with data on the dynamics of disease-induced defoliation and associated yield losses, could lead to development of treatment thresholds, using an approach similar to that used for Septoria diseases of wheat (36). Ultimately, this would have to incorporate other foliar diseases such as rust, anthracnose, and Gloeosporium leaf spot, which can affect certain blueberry cultivars in the southeastern United States (28). Potential interactions among these diseases and their relative effects on defoliation and yield need to be investigated.

TABLE 3. Parameter estimates and test statistics for accelerated failure time models describing the time to abscission of individual leaves of Premier rabbiteye blueberry in a field study in Georgia in 2002 and 2003

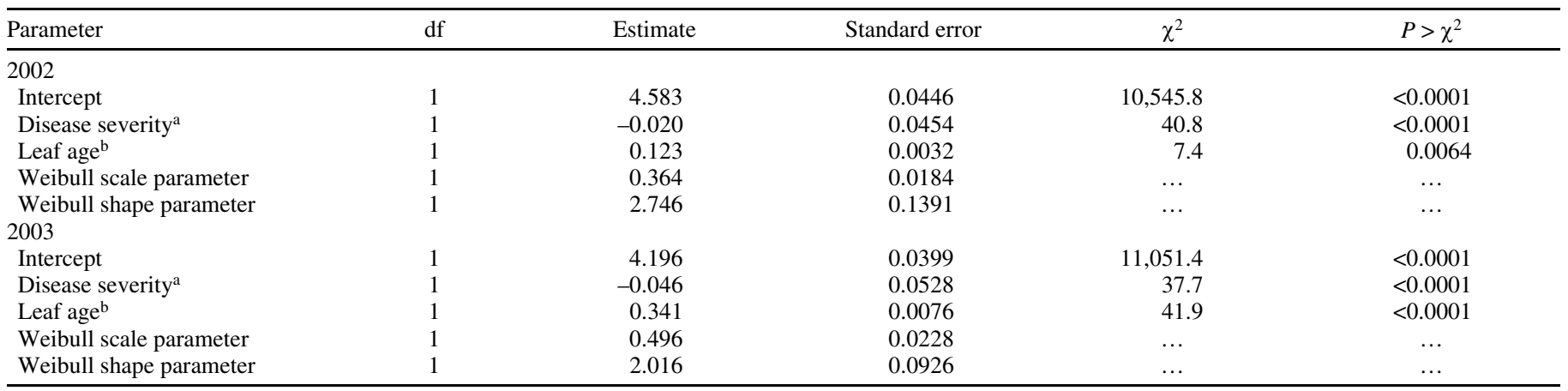

a Number of spots per leaf due to Septoria albopunctata in mid-June when $\approx 50 \%$ of the fruit had been harvested.

${ }^{\mathrm{b}}$ Coded as 0 and 1 for leaves on the lower (older leaves) or upper (younger leaves) halves of the assessed shoots, respectively. 


\section{ACKNOWLEDGMENTS}

Funded in part by MBG Marketing, the Southern Region Small Fruit Consortium, and the United States Department of Agriculture-CSREES Pest Management Alternatives Program (grant 01-34381-11181). We thank A. Savelle for assistance in data collection.

\section{LITERATURE CITED}

1. Allison, P. D. 1997. Survival Analysis Using the SAS System. A Practical Guide. SAS Institute, Cary, NC.

2. Austin, M. E. 1994. Rabbiteye Blueberries: Development, Production, and Marketing. Agscience, Auburndale, FL.

3. Boatright, S., and McKissick, J. 2003. Georgia Farm Gate Value Report 2002. AR03-01, University of Georgia Center for Agribusiness and Economic Development, Athens.

4. Brannen, P. M., Scherm, H., and Bruorton, M. D. 2002. Fungicidal control of Septoria leaf spot of blueberry, 2001. Fungic. Nematicide Tests 57:SMF46.

5. Brannen, P. M., Scherm, H., and Bruorton, M. D. 2003. Fungicidal control of Septoria leaf spot of blueberry, 2002. Fungic. Nematicide Tests 58:SMF019.

6. Choi, S. T., Park, D. S., Song, W. D., Kang, S. M., and Shon, G. M. 2003. Effect of different degrees of defoliation on fruit growth and reserve accumulation in young 'Fuyu' trees. Acta Hortic. 601:99-104.

7. Cline, W. O. 2002. Blueberry bud set and yield following the use of fungicides for leaf spot control in North Carolina. Acta Hortic. 574:71-74.

8. Dallot, S., Gottwald, T., Labonne, G., and Quiot, J.-B. 2004. Factors affecting the spread of Plum pox virus strain $\mathrm{M}$ in peach orchards subjected to roguing in France. Phytopathology 94:1390-1398.

9. Darnell, R. L. 1991. Photoperiod, carbon partitioning, and reproductive development in rabbiteye blueberry. J. Am. Soc. Hortic. Sci. 116:856-860.

10. Dungan, R. J., Duncan, R. P., and Whitehead, D. 2003. Investigating leaf lifespans with interval-censored failure time analysis. New Phytol. 158:593-600.

11. Harrell, F. E., Jr. 2001. Regression Modeling Strategies: With Applications to Linear Models, Logistic Regression, and Survival Analysis. Springer-Verlag, New York.

12. Hidalgo, H., Sutton, T. B., and Arauz, F. 1997. Epidemiology and control of citrus greasy spot on Valencia orange in the humid tropics of Costa Rica. Plant Dis. 81:1015-1022.

13. Hood, I. A., Chapman, S. J., Gardner, J. F., and Molony, K. 2002. Seasonal development of Septoria leaf blight in young Eucalyptus nitens plantations in New Zealand. Aust. For. 65:153-164.

14. Hoogenboom, G., and Gresham, D. D. 1997. Automated weather station network. Pages 483-486 in: Proc. Georgia Water Resources Conf. K. J. Hatcher, ed. Institute of Ecology, University of Georgia, Athens.

15. Jesus, W. C., Jr., Vale, F. X., Coelho, R. R., Paul, P. A., Hau, B., Bergamin Filho, A., Zambolim, L., and Berger, R. D. 2003. Relationship between angular leaf spot, healthy leaf area, effective leaf area and yield of Phaseolus vulgaris. Eur. J. Plant Pathol. 109:625-632.

16. Jules, E. S., Kauffman, M. J., Ritts, W. D., and Carroll, A. L. 2002. Spread of an invasive pathogen over a variable landscape: A nonnative root rot on Port Orford cedar. Ecology 83:3167-3181.

17. Lawless, J. F. 2003. Statistical Models and Methods for Lifetime Data, 2nd ed. Wiley, Hoboken, NJ.

18. Layne, D. R., and Flore, J. A. 1993. Physiological responses of Prunus cerasus to whole-plant source manipulation: Leaf gas exchange, chloro- phyll fluorescence, water relations and carbohydrate concentrations. Physiol. Plant 88:44-51.

19. Lopes, D. B., and Berger, R. D. 2001. The effect of rust and anthracnose on the photosynthetic capacity of diseased bean leaves. Phytopathology 91:212-220.

20. Lyrene, P. M. 1992. Early defoliation reduces flower bud counts on rabbiteye blueberry. HortScience 27:783-785.

21. Madden, L. V., and Nault, L. R. 1983. Differential pathogenicity of corn stunting mollicutes to leafhopper vectors in Dalbulus and Baldulus species. Phytopathology 73:1608-1614.

22. Milholland, R. D. 1995. Septoria leaf spot and stem canker. Page 16 in: Compendium of Blueberry and Cranberry Diseases. F. L. Caruso and D. C. Ramsdell, eds. The American Phytopathological Society, St. Paul, MN.

23. NeSmith, D. S., Krewer, G., and Williamson, J. G. 1998. A leaf bud developmental scale for rabbiteye blueberry (Vaccinium ashei Reade). HortScience 33:757.

24. Ojiambo, P. S., Scherm, H., and Brannen, P. M. 2002. Septoria leaf spot intensity, defoliation, and yield loss relationships in southern blueberries. (Abstr.) Phytopathology 92:1025.

25. Oliveira, C. M., and Priestly, A. 1988. Carbohydrate reserves in deciduous fruit trees. Hortic. Rev. 10:403-430.

26. Roloff, I., Scherm, H., and van Iersel, M. W. 2004. Photosynthesis of blueberry leaves as affected by Septoria leaf spot and abiotic leaf damage. Plant Dis. 88:397-401.

27. Rosenberger, D. A., Engle, C. A., and Meyer, F. W. 1996. Effect of management practices and fungicides on sooty blotch and flyspeck disease and productivity of Liberty apples. Plant Dis. 80:798-803.

28. Scherm, H., Brannen, P. M., Ojiambo, P. S., Savelle, A. T., Krewer, G., and Bruorton, M. D. 2003. Blueberry leaf spots: Epidemiology, yield losses, and control. Pages 57-66 in: Proc. Southeast. Blueberry Conf., Savannah, GA.

29. Scherm, H., and Krewer, G. 2003. Blueberry production in Georgia: Historical overview and recent trends. Small Fruits Rev. 2:83-91.

30. Scherm, H., and Ojiambo, P. S. 2004. Applications of survival analysis in botanical epidemiology. Phytopathology 94:1022-1026.

31. Sharma, I. M., and Bhardwaj, S. S. 2003. Efficacy and economics of different fungicide spray schedules in controlling premature defoliation disease in apple. Plant Dis. Res. 18:21-24.

32. Stokes, M. E., Davis, C. S., and Koch, G. G. 1995. Categorical Data Analysis Using the SAS System. SAS Institute, Cary, NC.

33. Sztejnberg, A. 1986. Etiology and control of cherry leaf spot disease in Israel caused by Cercospora circumscissa. Plant Dis. 70:349-351.

34. Titus, J. S., and Kang, S. M. 1981. Nitrogen metabolism, translocation and recycling in apple trees. Hortic. Rev. 4:204-246.

35. Vermerris, W., and McIntyre, L. M. 1999. Time to flowering in brown midrib mutants of maize: An alternative approach to the analysis of developmental traits. Heredity 83:171-178.

36. Verreet, J. A., Klink, H., and Hoffmann, G. M. 2000. Regional monitoring for disease prediction and optimization of plant protection measures: The IPM wheat model. Plant Dis. 84:816-826.

37. Westra, A. A. G., Arneson, C. P., and Slack, S. A. 1994. Effect of interaction of inoculum dose, cultivar, and geographic location on the development of foliar symptoms of bacterial ring rot of potato. Phytopathology 84:410-415.

38. Williamson, J. G., and Miller, E. P. 2002. Early and mid-fall defoliation reduces flower bud number and yield of southern highbush blueberry. HortTechnology 12:214-216.

39. Zens, M. S., and Peart, D. R. 2003. Dealing with death data: Individual hazards, mortality and bias. Trends Ecol. Evol. 18:366-373. 